\title{
Biological activities of vitreous gel, retrohyaloid fluid and subretinal fluid from diabetic and non-diabetic
}

\author{
eyes
}

\author{
Mike Boulton, Patrick Moriarty, Zdenek J Gregor
}

\begin{abstract}
This study compared the effects of vitreous gel, retrohyaloid fluid and subretinal fluid from diabetic and non-diabetic eyes on the proliferation and migration of retinal microvascular cells in vitro. Intraocular fluids were obtained from eyes undergoing repair of retinal detachment, due either to proliferative diabetic retinopathy or rhegmatogenous retinal detachment associated with a degree of proliferative vitreoretinopathy. The results demonstrated that the intraocular stimulatory activity for the proliferation of retinal microvascular endothelial cells varied between the different ocular compartments. The mitogenic and migrational activity in vitreous gel was greater than that of either the subretinal or retrohyaloid fluids of the same eye, and the activity of subretinal fluid was intermediate between that of the vitreous gel and the retrohyaloid fluid. There was no significant difference between the activities of the samples from diabetic and nondiabetic eyes.
\end{abstract}

The exact mechanism of preretinal neovascularisation and its regression after laser photocoagulation is unknown, but these events are thought to be modulated by a 'fine' balance of a variety of growth factors within the eye. ${ }^{12}$ Since Michaelson first postulated the existence of (and a role for) such biochemical factors in the process of neovascularisation, ${ }^{3}$ considerable effort has been expended in identifying the factor or factors responsible for these ocular manifestations.

When comparing the type and number of factors between normal eyes and eyes with vasoproliferative retinopathies the vitreous has proved a convenient source of material since it can be removed easily during surgical procedures and subsequently analysed in the laboratory for its biological activity. However, the vitreous gel (which is usually detached from the retina at the time of vitrectomy) $)^{4}$ may be some distance from the putative source of the factors in the ischaemic retina. It is therefore possible that the biological activity of the retrohyaloid fluid bathing the ischaemic retina may differ from that in the vitreous gel. Furthermore, eyes with associated tractional retinal detachment can give rise to a fluid filled subretinal space, the fluid of which has been 'conditioned' not only from the ischaemic retina but also from the retinal pigment epithelium. Similar fluid compartments exist in eyes with simple (idiopathic) rhegmatogenous detachment unassociated with neovascularisation but sometimes complicated by non-vascularised periretinal proliferation 'proliferative vitreoretinopathy' (PVR). ${ }^{4}$
To date vitreous samples from diabetic eyes have been shown to have an increased proliferative activity compared with normal vitreous. . $^{\text {s-9 }}$ However, there has been no comparison of the biological activities of fluids from the different intraocular compartments. Thus the aim of this study was to compare the effects of vitreous gel, retrohyaloid fluid, and subretinal fluid from diabetic and non-diabetic eyes on the proliferation and migration of retinal microvascular cells in vitro. Variations in such activity between the different compartments may have a bearing on the pathophysiology and location of the neovascular response.

\section{Materials and methods}

\section{ISOLATION OF INTRAOCULAR FLUIDS}

Samples of intraocular fluids were obtained at Moorfields Eye Hospital, London during vitrectomy in eyes undergoing repair of retinal detachment, due either to proliferative diabetic retinopathy ( 13 cases) or rhegmatogenous retinal detachment associated with a degree of proliferative vitreoretinopathy (eight cases). The diabetic patients had either tractional retinal detachment involving the macula or combined tractionrhegmatogenous detachment. All diabetic eyes had previously undergone scatter laser photocoagulation, but the exact extent of this treatment could not be readily quantified.

The non-diabetic patients had rhegmatogenous retinal detachment with signs of proliferative vitreoretinopathy (more than $\mathrm{C} 1) .{ }^{10}$ Vitrectomy was performed on these patients either because of the posterior position or large size of the break and/or in order to gain access to the contracted epiretinal membranes. Patients with retinal breaks underwent internal drainage of subretinal fluid during fluid:air exchange.

All diabetic patients had tractional retinal detachments involving the macula with no clinical evidence of intragel, retrohyaloid or subretinal haemorrhages (Table 1). Seven patients had 'pure' traction retinal detachments and six had combined traction-rhegmatogenous retinal detachments. Of the non-diabetic patients, four had proliferative retinopathy requiring epiretinal membrane dissection and four had large and/or posterior retinal breaks requiring internal tamponade. None of the patients studied had clinically recognisable haemorrhage in the vitreous or in the retrohyaloid space.

Undiluted vitreous gel was obtained at the start of the vitrectomy using a $5 \mathrm{ml}$ syringe connected to the vitreous cutter by a short length
Z J Gregor

Correspondence to:

Z J Gregor.

Accepted for publication

4 July 1991 
Table 1 Clinical details of patients

\begin{tabular}{lllllll}
\hline & \multicolumn{2}{l}{ Non-diabetic detachments } & & \multicolumn{2}{c}{ Diabetic detachments } \\
\cline { 2 - 3 } \cline { 5 - 6 } Patient & Type & $\begin{array}{c}\text { Duration } \\
\text { (weeks) }\end{array}$ & & Patient & Type & $\begin{array}{c}\text { Duration } \\
\text { (weeks) }\end{array}$ \\
\hline 1 & PVR $>$ D1 & 12 & 9 & COMB & 12 \\
2 & PVR $>$ D1 & 14 & 10 & TRD & 24 \\
3 & PVR <D1 & 6 & 11 & COMB & 8 \\
4 & PVR <D1 & 8 & 12 & TRD & 16 \\
5 & PVR <D1 & 8 & 13 & COMB & 12 \\
6 & PVR $>$ D1 & 16 & 14 & TRD & 24 \\
7 & PVR <D1 & 12 & 15 & TRD & 20 \\
8 & PVR <D1 & 20 & 16 & COMB & 12 \\
& & & 17 & COMB & 14 \\
& & & 18 & TRD & 28 \\
& & & 19 & TRD & 20 \\
& & & 20 & COMB & 8 \\
& & & 21 & TRD & 24 \\
\hline
\end{tabular}

$\mathrm{PVR}=$ proliferative vitreoretinopathy $(>\mathrm{Dl}=$ greater than stage $\mathrm{D} ;<\mathrm{Dl}=$ stages $\mathrm{Cl}$ to $\mathrm{C} 4)$; $\mathrm{COMB}=$ combined traction and rhegmatogenous detachment; TRD= traction retinal detachment without retinal breaks.

of tubing. The cutter was activated in the midvitreous cavity and approximately $0.7 \mathrm{ml}$ of nonhaemorrhagic vitreous was aspirated.

Undiluted retrohyaloid fluid was obtained through a small incision in the partially separated posterior hyaloid face. A 20 gauge blunt needle was attached to a $1 \mathrm{ml}$ syringe in which a side opening had been made previously. The end of the needle was inserted through the opening in the hyaloid face and the intraocular infusion of Hartman's solution was started. The increased intraocular pressure allowed the retrohyaloid fluid to enter the collection syringe; $0.7 \mathrm{ml}$ of non-haemorrhagic retrohyaloid fluid was thus obtained.

A volume of $0.3-0.5 \mathrm{ml}$ of subretinal fluid was secured during internal drainage and hydraulic retinal reattachment by fluid-gas exchange using a similar collection system to that employed for recovery of retrohyaloid fluid.

All syringes containing samples were sealed with appropriate stoppers and sent immediately to the laboratory where they were stored at $-70^{\circ} \mathrm{C}$ until required.

\section{PREPARATION OF VITREOUS SAMPLES}

Before use the vitreous samples were thawed and liquefied by aspiration through a 27 gauge needle. Owing to the small quantity of material the samples were diluted to an appropriate concentration in the test media and filter sterilised through a $0.22 \mu \mathrm{m}$ filter (Millipore. USA).

\section{CELL CULTURE}

Bovine retinal microvascular endothelial cells were grown in a 1:1 mixture of Dulbecco's modified Eagle's Medium (DMEM) with $7 \cdot 5 \%$ human platelet-poor plasma and pericyteconditioned medium. ${ }^{11}$

Cultures between the second and third passage were used for all subsequent studies.

\section{PROLIFERATION ASSAYS}

A total of $2 \times 10^{4}$ retinal microvascular endothelial cells were seeded into each gelatinised well of 24 well plates (Flow) in DMEM supple- mented with $7 \cdot 5 \%$ human platelet-poor plasma. After a period of 24 hours to allow for attachment and initial proliferation the medium was removed and the cells were washed twice with plasma-free DMEM. Each well then received $1 \mathrm{ml}$ of DMEM $+7 \cdot 5 \%$ human platelet poor plasma to which had been added $100 \mu \mathrm{l}$ of liquefied vitreous gel, subretinal fluid, or retrohyaloid fluid. Due to the limited quantity of material available samples were tested either in duplicate or triplicate. Control wells received $1 \mathrm{ml}$ of DMEM containing $100 \mu \mathrm{l}$ of Dulbecco's phosphate buffered saline without calcium and magnesium (PBSA). After 4 days in the test media cell numbers were determined using a haemocytometer.

Aliquots of cells from each test were stained with trypan blue in order to determine any cytotoxic effect.

\section{MIGRATION ASSAYS}

Migration assays were undertaken on representative samples as described by Singh et al using 48 well modified Boyden chambers. ${ }^{12}$ Briefly, the lower wells were filled with test media consisting of $100 \mu \mathrm{l} / \mathrm{ml}$ of either liquefied vitreous gel, subretinal fluid or retrohyaloid fluid added to plasma-free DMEM. Each test medium type was added to six wells. In control wells the intraocular fluid was substituted with an equivalent volume of PBSA. The wells were then overlaid with a type 1 collagen (Ethicon) coated polycarbonate membrane with $10 \mu \mathrm{m}$ pores and the chambers assembled. Upper wells were filled with a suspension of retinal microvascular endothelial cells in plasma-free medium at a cell density of $10^{\%} / 1$. The chambers were then incubated for 6 hours at $37^{\circ} \mathrm{C}$. The membrane was removed, fixed in methyl alcohol and stained with modified Wright's stain. The number of cells which had migrated through the polycarbonate membrane were counted after the non-migrated cells had been wiped from the top surface. Cell nuclei in 10 high power fields $(\times 40)$ were counted in each well.

\section{PROTEIN ASSAYS}

The protein content of the samples was determined using the Biorad Coomassie blue assay kit according to the manufacturers instructions.

\section{LACTATE MEASUREMENTS}

Due to the possibility of dilution of the retrohyaloid and subretinal samples by contamination with Hartman's buffer during infusion at surgery, levels of lactate (a major constituent of Hartman's) were measured in the Department of Clinical Biochemistry, Manchester Royal Infirmary.

\section{STATISTICS}

All data from the proliferation and migration experiments are expressed as mean (SD). Where possible the statistical significance of the data from the different samples was examined by analysis of variance. 
Table 2 The effect of vitrectomy samples from diabetic and 'non-diabetic patients on the proliferation of retinal capillary endothelial cells

\begin{tabular}{|c|c|c|c|c|c|}
\hline Patient no & $C$ & $V$ & $S$ & $R$ & Result $^{\mathrm{b}}$ \\
\hline \multicolumn{6}{|c|}{ Non-diabetic patients } \\
\hline 1 & $26 \cdot 0(2 \cdot 1)^{a}$ & $38 \cdot 0(4 \cdot 0)^{\mathrm{a}}$ & $23 \cdot 0(1 \cdot 8)^{\mathrm{a}}$ & - & $\mathrm{V}>\mathrm{S}$ \\
\hline 2 & $26 \cdot 0(2 \cdot 1)$ & $42 \cdot 0(5 \cdot 2)$ & $36 \cdot 0(3 \cdot 7)$ & - & $\mathrm{V}=\mathrm{S}$ \\
\hline 3 & $26 \cdot 0(2 \cdot 1)$ & $49 \cdot 4(6 \cdot 1)$ & $34 \cdot 0(4 \cdot 3)$ & - & $\mathrm{V}>\mathrm{S}$ \\
\hline 4 & $26 \cdot 0(2 \cdot 1)$ & $43 \cdot 4(4 \cdot 7)$ & - & $28 \cdot 0(2 \cdot 4)^{\mathrm{a}}$ & $\mathrm{V}>\mathrm{R}$ \\
\hline 5 & $26 \cdot 0(2 \cdot 1)$ & $28 \cdot 0(3 \cdot 3)$ & - & - & \\
\hline 6 & $26 \cdot 0(2 \cdot 1)$ & $47 \cdot 0(4 \cdot 5)$ & $39.4(3.9)$ & - & $\mathrm{V}=\mathrm{S}$ \\
\hline 7 & $26 \cdot 0(2 \cdot 1)$ & $27 \cdot 4(2 \cdot 5)$ & - & - & \\
\hline 8 & $26 \cdot 0(2 \cdot 1)$ & $34.0(2 \cdot 9)$ & $30 \cdot 0(3 \cdot 0)$ & - & $\mathrm{V}=\mathrm{S}$ \\
\hline \multicolumn{6}{|c|}{ Diabetic patients } \\
\hline 9 & $26 \cdot 0(2 \cdot 1)$ & $26 \cdot 6(2 \cdot 8)$ & - & $32 \cdot 0(2 \cdot 6)$ & $\mathbf{R}=\mathbf{V}$ \\
\hline 10 & $26 \cdot 0(2 \cdot 1)$ & $38 \cdot 0(2 \cdot 7)$ & $10 \cdot 0(4 \cdot 1)$ & $28 \cdot 0(1 \cdot 9)$ & $\mathrm{V}>\mathrm{R}>\mathrm{S}$ \\
\hline 11 & $26 \cdot 0(2 \cdot 1)$ & $50 \cdot 0(6 \cdot 1)$ & - & $31 \cdot 0(2 \cdot 4)$ & $V>R$ \\
\hline 12 & $26 \cdot 0(2 \cdot 1)$ & $49 \cdot 0(4 \cdot 3)$ & $31 \cdot 4(2 \cdot 0)$ & - & $\mathrm{V}>\mathrm{S}$ \\
\hline 13 & $26 \cdot 0(2 \cdot 1)$ & $50 \cdot 6(4 \cdot 5)$ & $50 \cdot 0(3 \cdot 5)$ & $29 \cdot 2(1 \cdot 7)$ & $\mathrm{V}=\mathrm{S}>\mathrm{R}$ \\
\hline 14 & $26 \cdot 0(2 \cdot 1)$ & $39 \cdot 4(2 \cdot 6)$ & - & $38.6(2 \cdot 4)$ & $\mathbf{V}=\mathbf{R}$ \\
\hline 15 & $26 \cdot 0(2 \cdot 1)$ & $58 \cdot 6(6 \cdot 8)$ & - & $31 \cdot 4(2 \cdot 5)$ & $\mathbf{V}>\mathbb{R}$ \\
\hline 16 & $26 \cdot 0(2 \cdot 1)$ & $35 \cdot 4(3 \cdot 3)$ & $2 \cdot 6(1 \cdot 2)$ & $24.6(1.8)$ & $V>R>S$ \\
\hline 17 & $26 \cdot 0(2 \cdot 1)$ & $44 \cdot 0(3 \cdot 8)$ & $37 \cdot 0(4 \cdot 8)$ & $28 \cdot 0(2 \cdot 2)$ & $\mathrm{V}=\mathrm{S}>\mathbf{R}$ \\
\hline 18 & $26 \cdot 0(2 \cdot 1)$ & $57 \cdot 0(4 \cdot 6)$ & - & $34 \cdot 0(2 \cdot 1)$ & $\mathbf{V}>\mathbf{R}$ \\
\hline 19 & $26 \cdot 0(2 \cdot 1)$ & $50.0(5.4)$ & - & $27 \cdot 0(2 \cdot 2)$ & $\mathbf{V}>\mathbf{R}$ \\
\hline 20 & $26 \cdot 0(2 \cdot 1)$ & $37 \cdot 0(3 \cdot 2)$ & $33.4(2.7)$ & $8.0(5.8)$ & $\mathbf{V}>\mathbf{S}>\mathbf{R}$ \\
\hline 21 & $26 \cdot 0(2 \cdot 1)$ & $42 \cdot 5(3 \cdot 1)$ & - & $31 \cdot 0(2 \cdot 1)$ & $\mathbf{V}>\mathbf{R}$ \\
\hline
\end{tabular}

astandard deviations (SD).

bStatistical comparisons between different samples from the same eye $(p<0.05$ is considered significant).

The mean number of cells $\left(\times 10^{3}\right)$ is given in each column. $\mathrm{C}=$ control; $\mathrm{V}=$ vitreous; $\mathrm{S}=$ subretina fluid; $R=$ retrohyaloid fluid.

\section{Results}

\section{PROLIFERATION}

Samples of vitreous gel from 12 of the 13 diabetic patients significantly stimulated the proliferation of retinal microvascular endothelial cells when compared with the control basal media (Table 2). By contrast 11 of the 12 retrohyaloid samples had proliferative activity similar to or only slightly more than that of the control basal media; the remaining sample showed less proliferative activity. Furthermore, the retrohyaloid fluid from 10 of 12 diabetic eyes exhibited significantly less mitogenic activity when compared with their respective vitreous gel samples. The results for the subretinal fluid were highly variable with some samples showing higher mitogenic activity than the control basal medium and others exhibiting less activity (Table 2). None of the subretinal fluid samples demonstrated greater proliferative activity than their respective vitreous gel samples. No cytotoxicity was observed in any of the test media using the trypan blue exclusion test but in some instances in which the final cell numbers were less than those in the basal medium, unstained cells could

Table 3 The effect of vitrectomy samples from diabetic and non-diabetic patients on the migration of retinal capillary endothelial cells

\begin{tabular}{|c|c|c|c|c|c|c|}
\hline Patient no & $0 \% D M E M$ & $V$ & $S$ & $R$ & $7 \cdot 5 \%$ DMEM & Result $^{\mathrm{b}}$ \\
\hline \multicolumn{7}{|c|}{ Non-diabetic patients } \\
\hline 1 & $10 \cdot 7(1.6)^{2}$ & $20 \cdot 2(1 \cdot 3)^{a}$ & $8 \cdot 1(0 \cdot 6)^{2}$ & - & $49 \cdot 7(5 \cdot 2)^{a}$ & $\mathrm{~V}>\mathrm{S}$ \\
\hline 2 & $10.7(1 \cdot 6)$ & $43.6(3.4)$ & $42 \cdot 2(2 \cdot 8)$ & - & $49 \cdot 7(5 \cdot 2)$ & $\mathrm{V}=\mathrm{S}$ \\
\hline 3 & $10.7(1.6)$ & $15 \cdot 7(1 \cdot 0)$ & $25 \cdot 1(1 \cdot 8)$ & - & $49 \cdot 7(5 \cdot 2)$ & $\mathrm{S}>\mathrm{V}$ \\
\hline 4 & $10 \cdot 7(1 \cdot 6)$ & $22 \cdot 2(1 \cdot 7)$ & - & $9.9(0.5)$ & $49 \cdot 7(5 \cdot 2)$ & $\mathbf{V}>\mathbf{R}$ \\
\hline \multicolumn{7}{|c|}{ Diabetic patients } \\
\hline 9 & $10 \cdot 7(1 \cdot 6)$ & $8 \cdot 1(0.4)$ & - & $9 \cdot 3(0.5$ & $49 \cdot 7(5 \cdot 2)$ & $V=R$ \\
\hline 13 & $10 \cdot 7(1 \cdot 6)$ & $24 \cdot 8(1 \cdot 6)$ & $8 \cdot 1(0 \cdot 7)$ & $11 \cdot 4(0.9)$ & $49 \cdot 7(5 \cdot 2)$ & $\mathbf{V}>\mathbf{R}>\mathbf{S}$ \\
\hline 15 & $10 \cdot 7(1 \cdot 6)$ & $27 \cdot 7(2 \cdot 1)$ & - & $3 \cdot 1(0 \cdot 2)$ & $49 \cdot 7(5 \cdot 2)$ & $\mathbf{V}>\mathbf{R}$ \\
\hline 17 & $10.7(1.6)$ & $17 \cdot 9(0.8)$ & $15 \cdot 5(1 \cdot 1)$ & $12 \cdot 6(0 \cdot 6)$ & $49 \cdot 7(5 \cdot 2)$ & $\mathrm{V}>\mathrm{S}=\mathrm{R}$ \\
\hline 18 & $10 \cdot 7(1.6)$ & $42 \cdot 9(3 \cdot 7)$ & & $23 \cdot 3(2 \cdot 0)$ & $49 \cdot 7(5 \cdot 2)$ & $\mathbf{V}>\mathbf{R}$ \\
\hline
\end{tabular}

${ }^{A}$ Standard deviations (SD).

bStatistical comparisons between different samples from the same eye $(\mathrm{p}<0.05$ is considered statistical comicant).

The mean number of cells per high power fields is given in each column. $V=$ vitreous; $S=$ subretinal fluid; $\mathbf{R}=$ retrohyaloid fluid. be observed floating in the medium (patients 10 , 16 , and 20).

Results from the non-diabetic samples were inconsistent (Table 2). The vitreous gel stimulated cell proliferation in six of the eight cases and had no effect in the other two. The one retrohyaloid fluid sample that was obtained had lower mitogenic activity than the corresponding vitreous gel but the same activity as the control basal medium. The subretinal fluid samples exhibited either similar or less activity than their corresponding vitreous samples.

\section{MIGRATION}

With the exception of one diabetic vitreous sample (patient 9) all the vitreous samples tested stimulated endothelial cell migration when compared with serum free media (Table 3). Again with the exception of patient 9 cell migration was greater in the vitreous gel samples than the corresponding retrohyaloid fluids. In four of the six retrohyaloid samples cell migration was similar to that observed with basal medium, while one had increased migration and the other decreased migration compared with the control medium. The capability of subretinal fluid samples to promote cell migration was variable; some samples stimulated cell migration while others gave values similar to that of the baseline control.

PROTEIN CONCENTRATIONS

The protein concentrations of the vitreous samples, both diabetic and non-diabetic, ranged from 175 to $2300 \mathrm{mg} / \mathrm{ml}$ (Table 4). In 10 of 13 diabetic patients the protein concentrations in the retrohyaloid fluids were less than the concentrations in the corresponding vitreous gel samples. In only one patient (patient 10 ) was the protein concentration of the retrohyaloid fluid greater than that in the corresponding vitreous gel sample. The protein concentrations of the subretinal fluids were variable with values ranging from 20 to $2550 \mathrm{mg} / \mathrm{ml}$. In general the

Table 4 Protein concentration ( $m g / l)$ in vitrectomy samples from diabetic and non-diabetic patients

\begin{tabular}{|c|c|c|c|c|}
\hline Patient no & $V$ & $S$ & $R$ & Result ${ }^{a}$ \\
\hline \multicolumn{5}{|c|}{ Non-diabetic patients } \\
\hline 1 & 2068 & 20 & - & $\mathrm{V}>\mathrm{S}$ \\
\hline 2 & 1860 & 2240 & - & $S>V$ \\
\hline 3 & 1550 & 1843 & - & $S>V$ \\
\hline 4 & 850 & - & 135 & $\mathbf{V}>\mathbf{R}$ \\
\hline 5 & 255 & - & - & \\
\hline 6 & 2375 & 2550 & - & $\mathrm{V}=\mathrm{S}$ \\
\hline 7 & 550 & - & - & \\
\hline 8 & 1430 & 2060 & - & $S>V$ \\
\hline \multicolumn{5}{|c|}{ Diabetic patients } \\
\hline 9 & 700 & - & 205 & $\mathrm{~V}>\mathrm{R}$ \\
\hline 10 & 175 & 2500 & 445 & $S>R>V$ \\
\hline 11 & 1410 & - & 860 & $\mathrm{~V}>\mathrm{R}$ \\
\hline 12 & 1460 & 50 & - & $\mathrm{V}>\mathrm{S}$ \\
\hline 13 & 1640 & 690 & 690 & $\mathrm{~V}>\mathrm{S}=\mathrm{R}$ \\
\hline 14 & 2300 & - & 2350 & $\mathrm{~V}=\mathrm{R}$ \\
\hline 15 & 1850 & _ & 50 & $V>R$ \\
\hline 16 & 790 & 2550 & 20 & $\mathrm{~S}>\mathrm{V}>\mathrm{R}$ \\
\hline 17 & 1700 & 895 & 420 & $\mathrm{~V}>\mathrm{S}>\mathrm{R}$ \\
\hline 18 & 2135 & - & 1650 & $\mathrm{~V}>\mathrm{R}$ \\
\hline 19 & 2035 & - & 1760 & $\mathrm{~V}>\mathrm{R}$ \\
\hline 20 & 1110 & 850 & 345 & $\mathrm{~V}>\mathrm{S}>\mathrm{R}$ \\
\hline 21 & 2000 & - & 90 & $\mathbf{V}>\mathbf{R}$ \\
\hline
\end{tabular}

${ }^{2}$ Statistical comparisons between different samples from the same

eye $(p<0.05$ is considered significant).
$V=$ vitreous; $S=$ subretinal fluid; $R=$ retrohyaloid fluid. 
Table 5 Comparison of proliferative activity, migratory activity and protein content of diabetic and non-diabetic samples

\begin{tabular}{|c|c|c|c|}
\hline Patient no & $\begin{array}{l}\text { Proliferative } \\
\text { activity }\end{array}$ & $\begin{array}{l}\text { Migratory } \\
\text { activity }\end{array}$ & $\begin{array}{l}\text { Protein } \\
\text { content }\end{array}$ \\
\hline \multicolumn{4}{|c|}{ Non-diabetic patients } \\
\hline 1 & $\mathrm{~V}>\mathrm{S}$ & $\mathrm{V}>\mathrm{S}$ & $\mathrm{V}>\mathrm{S}$ \\
\hline 2 & $\mathrm{~V}=\mathrm{S}$ & $\mathrm{V}=\mathrm{S}$ & $\mathrm{S}>\mathrm{V}$ \\
\hline 3 & $\mathrm{~V}=\mathrm{S}$ & $S>V$ & $\mathrm{~S}>\mathrm{V}$ \\
\hline 4 & $\mathbf{V}=\mathbf{R}$ & $V>R$ & $\mathrm{~V}>\mathbf{R}$ \\
\hline 5 & - & - & - \\
\hline 6 & $\mathrm{~V}>\mathrm{S}$ & - & $\mathrm{V}=\mathrm{S}$ \\
\hline 7 & - & - & - \\
\hline 8 & $\mathrm{~V}>\mathrm{S}$ & - & $S>V$ \\
\hline \multicolumn{4}{|l|}{ Diabetic patients } \\
\hline & $\mathbf{V}=\mathbf{R}$ & $V=R$ & $\mathrm{~V}>\mathrm{R}$ \\
\hline 10 & $\mathbf{V}>\mathbf{R}>\mathrm{S}$ & - & $S>R>V$ \\
\hline 11 & $\mathrm{~V}>\mathrm{R}$ & - & $\mathbf{V}>\mathbf{R}$ \\
\hline 12 & $\mathrm{~V}>\mathrm{S}$ & - & $\mathrm{V}>\mathrm{S}$ \\
\hline 13 & $\mathrm{~V}=\mathrm{S}>\mathrm{R}$ & $\mathrm{V}>\mathrm{S}>\mathrm{R}$ & $\mathrm{V}>\mathrm{S}=\mathrm{R}$ \\
\hline 14 & $\mathbf{V}=\mathbf{R}$ & - & $\mathbf{V}=\mathbf{R}$ \\
\hline 15 & $\mathbf{V}>\mathbf{R}$ & $\mathbf{V}>\mathbf{R}$ & $\mathrm{V}>\mathrm{R}$ \\
\hline 16 & $\mathrm{~V}>\mathrm{R}>\mathrm{S}$ & - & $\mathrm{S}>\mathrm{V}>\mathrm{R}$ \\
\hline 17 & $\mathrm{~V}=\mathrm{S}>\mathrm{R}$ & $\mathrm{V}>\mathrm{S}=\mathbf{R}$ & $\mathrm{V}>\mathrm{S}>\mathrm{R}$ \\
\hline 18 & $\mathbf{V}>\mathbf{R}$ & $\mathrm{V}>\mathrm{R}$ & $\mathrm{V}=\mathrm{R}$ \\
\hline 19 & $\mathrm{~V}>\mathbf{R}$ & - & $\mathrm{V}>\mathrm{R}$ \\
\hline 20 & $\mathrm{~V}=\mathrm{S}>\mathrm{R}$ & - & $\mathrm{V}>\mathrm{S}>\mathrm{R}$ \\
\hline 21 & $\mathrm{~V}>\mathrm{R}$ & - & $\mathrm{V}>\mathrm{R}$ \\
\hline
\end{tabular}

$\mathrm{V}=$ vitreous; $\mathrm{S}=$ subretinal fluid; $\mathrm{R}=$ retrohyaloid fluid. The columns show the statistical comparisons between different samples from the same eye $(\mathrm{p}<0.05$ is considered significant $)$

protein content of the subretinal fluid was higher than that of the respective retrohyaloid fluid but no correlation could be made with the vitreous gel samples.

When comparing the proliferative activity, migratory activity and protein content of the intravitreal samples the correlation between the different parameters was positive overall for eight out of 13 patients (diabetic and nondiabetic) and for 10 out of 13 patients when comparing vitreous with retrohyaloid fluid (Table 5). No correlation could be found for the subretinal fluid samples.

\section{LACTATE LEVELS}

In order to determine if the low biological activity in the retrohyaloid and subretinal fluids was due to dilution by Hartman's buffer during infusion at surgery, lactate levels were measured in representative samples of the different fluids. The lactate concentration in Hartman's buffer was $29 \mathrm{mmol} / \mathrm{l}$. The lactate levels in the vitreous gel ranged from 3.0 to $5.8 \mathrm{mmol} / 1$ while they were significantly greater $(\mathrm{p}<0.005)$ in the retrohyaloid fluid ranging from $5 \cdot 1$ to $9 \cdot 2 \mathrm{mmol} / \mathrm{l}$ (Table 6). If the differential between the lactate content in the vitreous and the retrohyaloid fluid reflected contamination by Hartman's buffer the dilution factor would range from $4 \cdot 8$ to $12 \%$. The

Table 6 Lactate levels in vitrectomy samples from diabetic and non-diabetic patients

\begin{tabular}{|c|c|c|c|}
\hline Patient no & V & $S$ & $R$ \\
\hline \multicolumn{4}{|c|}{ Non-diabetic patients } \\
\hline 1 & $5 \cdot 8$ & $11 \cdot 2$ & - \\
\hline 3 & $5 \cdot 8$ & $9 \cdot 7$ & - \\
\hline 4 & $4 \cdot 4$ & - & - \\
\hline \multicolumn{4}{|c|}{ Diabetic patients } \\
\hline 9 & $5 \cdot 7$ & - & $9 \cdot 2$ \\
\hline 13 & $3 \cdot 0$ & - & $5 \cdot 1$ \\
\hline 14 & $5 \cdot 0$ & - & $8 \cdot 4$ \\
\hline 18 & $5 \cdot 4$ & - & $6 \cdot 8$ \\
\hline 20 , & $3 \cdot 0$ & - & $5 \cdot 1$ \\
\hline \multicolumn{4}{|c|}{$($ Hartman's buffer $=29 \mathrm{mmol} / \mathrm{l})$} \\
\hline
\end{tabular}

Values are given as $\mathrm{mmol} / \mathrm{l}$ of lactate. $\mathrm{V}=$ vitreous; $\mathrm{S}=$ subretinal fluid; $\mathbf{R}=$ retrohyaloid fluid lactate levels in the two subretinal fluid samples tested $(9.7$ and $11.2 \mathrm{mmol} / \mathrm{l})$ were higher than those in either the vitreous gel samples or the retrohyaloid fluids.

\section{Discussion}

This study demonstrates that intraocular stimulatory activity varies between the different intraocular compartments in eyes undergoing vitrectomy for retinal detachment. The mitogenic and migrational activity in vitreous gel was greater than that of either the subretinal or retrohyaloid fluids of the same eye, while the activity of subretinal fluid was generally intermediate between that of the vitreous gel and the retrohyaloid fluid. An obvious explanation for the lower activities in retrohyaloid and subretinal fluids compared with vitreous gels is that these samples may be diluted by Hartman's solution used as the infusion during surgery. However this was not the case since the slight increase in lactate levels in samples taken after Hartman's infusion commenced at surgery was insufficient to account for the large differences in biological activity between the different intraocular compartments in individual eyes. The levels of lactate in the vitreous gel were similar to those previously reported for normal human vitreous ${ }^{13}$ (even though lactate levels are known to increase in certain disease conditions). ${ }^{14}$ Thus if the increase in lactate observed in the retrohyaloid and subretinal fluids is related to the disease process and not to the infusion fluid the differences in activity would be much greater. Whilst the protein concentrations in the vitreous gel and retrohyaloid samples were highly variable between different eyes the general trend was for the protein content of the retrohyaloid fluid to be lower than that of the vitreous gel from the corresponding eye. The highly variable protein content of the subretinal fluid samples could be explained by the duration of the detachment.

Interestingly there was no significant difference between the activities of the samples from diabetic and non-diabetic patients. This is contrary to previous studies which have shown that the mitogenic activity of intraocular fluid is raised in diabetic eyes compared with nondiabetic eyes. ${ }^{569}$ One explanation is that the nondiabetic patient group had active PVR and stimulatory activity would be expected to be present. However the factors present may differ between the two groups. Campochiaro et al demonstrated that the stimulation of retinal pigment epithelial migration by vitreous aspirates from patients with PVR was greater than that in aspirates from macular puckers and uncomplicated detachments. ${ }^{7}$ This supports the possibility that the non-diabetic PVRs are rich in stimulatory activity.

The reason why the biological activities were greatest in the vitreous gel is unclear. Although many of the stimulatory factors are thought to orginate from the retina other sources during retinal pathologies could include leakage from preretinal vessels and the release of factors from cells in or associated with the preretinal vessels growing in the cortical gel. ${ }^{12}$ The higher levels of activity in the vitreous gel compared with the 
retrohyaloid and subretinal compartments could be explained in a number of ways. Firstly, the molecular sieve properties of the gel could trap factors within the vitreous and thus cause the build up of a concentration gradient. ${ }^{15}$ Secondly, since many growth factors are bound to extracellular matrix components ${ }^{16}$ it is possible that retina/RPE derived growth factors become bound to components in the vitreous gel and thus reach a high concentration. Thirdly, the balance between stimulatory and inhibitory activity in the vitreous may be altered during pathological conditions. The results presented do not indicate if the greater biological activity in the vitreous is due to increased stimulatory activity or a decrease in inhibitory activity. Fourthly, the lower activities in the retrohyaloid and subretinal fluids could be explained by the fact that these fluids are closer to retinal cells that consume growth factors than is the vitreous.

This research was funded by the Guide Dogs for the Blind Association. The authors are grateful to Professor David McLeod for his helpful comments during the preparation of this manuscript.

1 Boulton ME, McLeod D, Garner A. Vasoproliferative retinopathies: clinical, morphogenetic and modulatory aspects. Eye 1988; 2: S124-39.

2 Glaser BM. Extracellular modulating factors and the control of intraocular neovascularisation: an overview. Arch Ophthalmol 1988; 106: 603-7.
3 Michaelson IC. The mode of development of the vascular system of the retina, with some observation for its signific ance for certain retinal diseases. Trans Ophthalmol Soc UK 1948; 68: $137-80$

4 Kanski JJ. Clinical ophthalmology. London: Butterworths, 1989.

5 Taylor CM, Kissun AM, Schor AM, McLeod D, Garner A, Weiss JB. Endothelial cell-stimulating factor from extraretinal neovascularisation. Invest Ophthalmol Vis Sci 1989; 30: $2174-8$.

6 Lutty JA, Chandler C, Bennett A, Fait C, Patz A. Presence of endothelial cell growth factor activity in normal and diabetic vitreous. Curr Eye Res 1986; 5: 6-17.

7 Campochiaro PA, Jerdan JA, Glaser BM, Cardin A, Michels RG. Vitreous aspirates from patients with proliferative RG. Vitreous aspirates from patients with proliferative
vitreoretinopathy stimulate retinal pigment epithelial cell vitreoretinopathy stimulate retinal pigment ep
migration. Arch Ophthalmol 1985; 103: 1403-5.

8 Baird A, Coller F, Jones K, Guillemin R. Angiogenic factor in human ocular fluid. Lancet 1985; ii: 563.

9 Grant M, Russell B, Fitzgerald C, Merimee TJ. Insulin-like growth factors in vitreous: studies in controls and diabetics with neovascularisation. Diabetes 1986; 35: 416-22.

10 Retina Society Terminology Committee. The classification of retinal detachment with proliferative vitreoretinopathy. Ophthalmology 1987; 90: 121-5.

11 Wong HC, Boulton M, Marshall J, Clark P. Growth of retinal capillary endothelia using pericyte conditioned medium. Invest Ophthalmol Vis Sci 1978; 28: 1767-75.

12 Singh A, Boulton M, Lane C, Forrester J, Gaal J, McLeod D. Inhibition of microvascular endothelial cell proliferation by vitreous following retinal scatter photocoagulation. $\mathrm{Br} \mathcal{F}$ vitreous following retinal scal

13 Imre G. The role of lactic acid in the mechanism of neovascularisation. In: BenEzra D, Ryan SJ, Glaser BM, Murphy $\mathrm{RP}$, eds. Ocular circulation and neovascularisation. The Hague: Martinus Nijhoff/W Junk, 1987: 511-6.

14 Gloor BP. The vitreous. In: Moses RA, Hart MH, eds. Adler's physiology of the eye. St Louis: Mosby, 1987: 246-67.

15 Balacz EA. The molecular biology of the vitreous. In: McPherson A, ed. New and controversial aspects of retinal detachment. New York: Harper and Row, 1968: 3-21.

16 Baird A, Walicke PA. Fibroblast growth factors. Br Med Bull 1989; 45: 438-52. 